\title{
Investigation of Lab Fire Prevention Management System of Combining Root Cause Analysis and Analytic Hierarchy Process with Event Tree Analysis
}

\author{
Cheng-Chan Shih, ${ }^{1}$ Richard S. Horng, ${ }^{2}$ and Shin-Ku Lee ${ }^{3}$ \\ ${ }^{1}$ Department of Occupational Safety and Hygiene, Fooyin University, No. 151 Chin-Hsueh Road, Ta-Liao, Kaohsiung 831, Taiwan \\ ${ }^{2}$ Department of Chemical Engineering, I-Shou University, No. 1, Sec. 1, Syuecheng Road, Dashu, Kaohsiung 840, Taiwan \\ ${ }^{3}$ Research Center of Energy Technology and Strategy, National Cheng Kung University, No. 1, University Road, Tainan 701, Taiwan \\ Correspondence should be addressed to Shin-Ku Lee; sklee1015@gmail.com
}

Received 17 February 2016; Accepted 22 May 2016

Academic Editor: Egidijus R. Vaidogas

Copyright (c) 2016 Cheng-Chan Shih et al. This is an open access article distributed under the Creative Commons Attribution License, which permits unrestricted use, distribution, and reproduction in any medium, provided the original work is properly cited.

\begin{abstract}
This paper proposed a new approach, combining root cause analysis (RCA), analytic hierarchy process (AHP), and event tree analysis (ETA) in a loop to systematically evaluate various laboratory safety prevention strategies. First, 139 fire accidents were reviewed to identify the root causes and draw out prevention strategies. Most fires were caused due to runaway reactions, operation error and equipment failure, and flammable material release. These mostly occurred in working places of no prompt fire protection. We also used AHP to evaluate the priority of these strategies and found that chemical fire prevention strategy is the most important control element, and strengthening maintenance and safety inspection intensity is the most important action. Also together with our surveys results, we proposed that equipment design is also critical for fire prevention. Therefore a technical improvement was propounded: installing fire detector, automatic sprinkler, and manual extinguisher in the lab hood as proactive fire protections. ETA was then used as a tool to evaluate laboratory fire risks. The results indicated that the total risk of a fire occurring decreases from 0.0351 to 0.0042 without/with equipment taking actions. Establishing such system can make Environment, Health and Safety $(\mathrm{EH} \& \mathrm{~S})$ office not only analyze and prioritize fire prevention policies more practically, but also demonstrate how effective protective equipment improvement can achieve and the probabilities of the initiating event developing into a serious accident or controlled by the existing safety system.
\end{abstract}

\section{Introduction}

Laboratory operations are dangerous that require all workers to act properly at all times. Most organizations or universities have set up an Environment, Health and Safety (EH\&S) office to protect people from accidents. They draw policies, develop programs, establish training and standard operating procedures (SOPs), and enforce their compliance to meet this goal $[1,2]$. Despite this, laboratory accidents still continue to occur. The most common type of accidents that occur in laboratories is fires. There have been 25 serious fires in laboratories, each of which incurred losses in excess of 13 million GBP, since 1997 [3]. Sometimes, even if a laboratory accident does not cause any fatalities, or injuries, significant property damage $[4,5]$ could make such events devastating, if they result in research samples and experimental models being destroyed as well as the data loss from many years of hard work. For example, a laboratory fire occurred in National Taiwan Ocean University on July 23, 2004 [6]; while no one was injured, the loss of property was estimated to be 100,000 US dollars. But the valuable observation data obtained on the ecology of green turtles (Chelonia mydas) from 1994 to 2004 was totally destroyed. An approach based on merely established rules, regulations, and instructions 
in safety manuals is unsatisfactory for valuable property protection. A proactive approach with control parameters to objectively measure its success is necessary.

The causes of laboratory accidents are usually very complex. Root cause analysis (RCA) provides a structural way, with regard to a particular event, to help investigators systematically identify root causes. Chang and Lin [7] reviewed 242 accidents of storage tanks that occurred over the last 40 years and found that fire and explosion accounted for $85 \%$ of the accidents. They used fishbone diagram to demonstrate the causes and effects; there are 8 primary causes and 52 secondary causes; six (6) major corrective actions and 40 secondary actions were also developed. Safety managers can establish protocols based on this complex information to help operating engineers handling similar situations in the future. However, they also need a way to estimate the impact of each cause and human corrective action for policy making. The analytic hierarchy process (AHP), proposed by Saaty [8], is a well-recognized multicriteria tool designed for dealing with complex decision-making problems. It models the problem into a hierarchical structure by incorporating levels: objectives (goals), criteria, subcriteria, and alternatives [9], and then, according to expert judgments, AHP estimates the impact of the elements at each level of the hierarchy [8-11]. This will help policy makers to make priority decisions. AHP has been widely applied to numerous fields for strategy planning, such as energy policy $[12,13]$, intelligent building systems [14], indicator modeling [15, 16], fire safety engineering [17], and evaluations of disaster carrying capacity [18]. However, the process is considered very subjective and needs a quantitative approach to objectively determine the probability of whether or not an initiating event still develops into a serious accident; most accidents are not due to a single event, but the results of many unnoticed events previously occurred. Event tree analysis (ETA) is an inductive technique intended to examine a sequence of events and their probability of occurrence. Several research works have been conducted using ETA for different applications. For instance, Novack et al. [19] used ETA to analyze accident scenarios attributed to oil spills. Abdelgawad and Fayek [20] proposed a hybrid framework based on combining failure mode and effect analysis (FMEA), fault trees, event trees, and fuzzy logic to calculate the expected monetary value of risk events in the construction industry. This method is useful as an objective decision making, where causes and effects are comprehensively taken into consideration when planning prevention actions. Many other risk management systems have also been proposed [21-26] elsewhere to carry out operating process risk assessments in laboratories, testing grounds, and practice factories.

Although many risk assessment methods have been proposed, few investigators have performed full risk or accident analyses and concept development, especially for college laboratory accidents. In this work, a management model combining RCA, AHP, and ETA is proposed. It contains risk concept development, decision-making process, and probability evaluation of various accident scenarios; fire accidents are chosen to demonstrate the feasibility of the proposed approach. We believe that it is a more effective system-based approach than the traditional one that is prescriptive based on safety manuals.

\section{Methodology}

Figure 1 illustrates this methodology, which is composed of five main steps. The first is to define the type of fire and fire source based on a general description of a large number of lab fire accidents in the literature. Then, in the second step, all this information is summarized using RCA to identify the root causes of the accident and to provide feasible accident prevention strategies. The third step is to analyze the priority of these strategies using AHP. Finally, ETA is used to complete the quantitative risk analysis and to assess each control measure recommended in this work. The research methods are described as follows.

2.1. Root Cause Analysis. In this study, an RCA task performance team was formed consisting of one EH\&S officer, one expert from the Ministry of Education Environmental Protection Division, and three college professors. Information on 139 laboratory fire accidents that occurred in Taiwan was reviewed from published reports and incident news and books $[4,6,23]$. It is important to clearly define the source of risk (what started the fire), causes of the fires (established or assumed), and consequences. The data in the references were first collected and discussed and then analyzed to identify the root causes, construct the fishbone diagram, and propose prevention strategies.

2.2. The AHP Method. Two surveys were conducted in the second phase of AHP analysis: a general survey and an AHP survey. The general survey was to investigate the effects of current laboratory safety education/training and knowledge of the safety facility system. Two questions about laboratory safety education were used to assess the respondents' reactions to the laboratory safety education and three questions to assess their knowledge of the location, SOPs, and operating experience of the fire sprinkler system. The respondents were required to read the statements and indicate the extent of their agreement or disagreement using a five-point Likert-type, with 5 denoting "strongly agree." The questionnaires were given to the respondents via e-mail or personal visit. The AHP approach was used to assign weightings to the prevention strategies proposed in the first phase to improve laboratory fire safety and to prioritize them using a set of criteria. A decision hierarchy was first established before designing the paired comparison matrices. The AHP questionnaire was designed for data collection, and the format was developed with reference to the AHP matrix, as proposed by Saaty [8]. A total of 15 experienced respondents were selected to complete the AHP questionnaire. The demographic information revealed that all the respondents were highly experienced in different professional positions, with more than five years of work experience in laboratory safety management. When examining the consistency level of the collected questionnaires, only a consistency ratio (CR) less than 0.1 is considered acceptable. The relative importance 


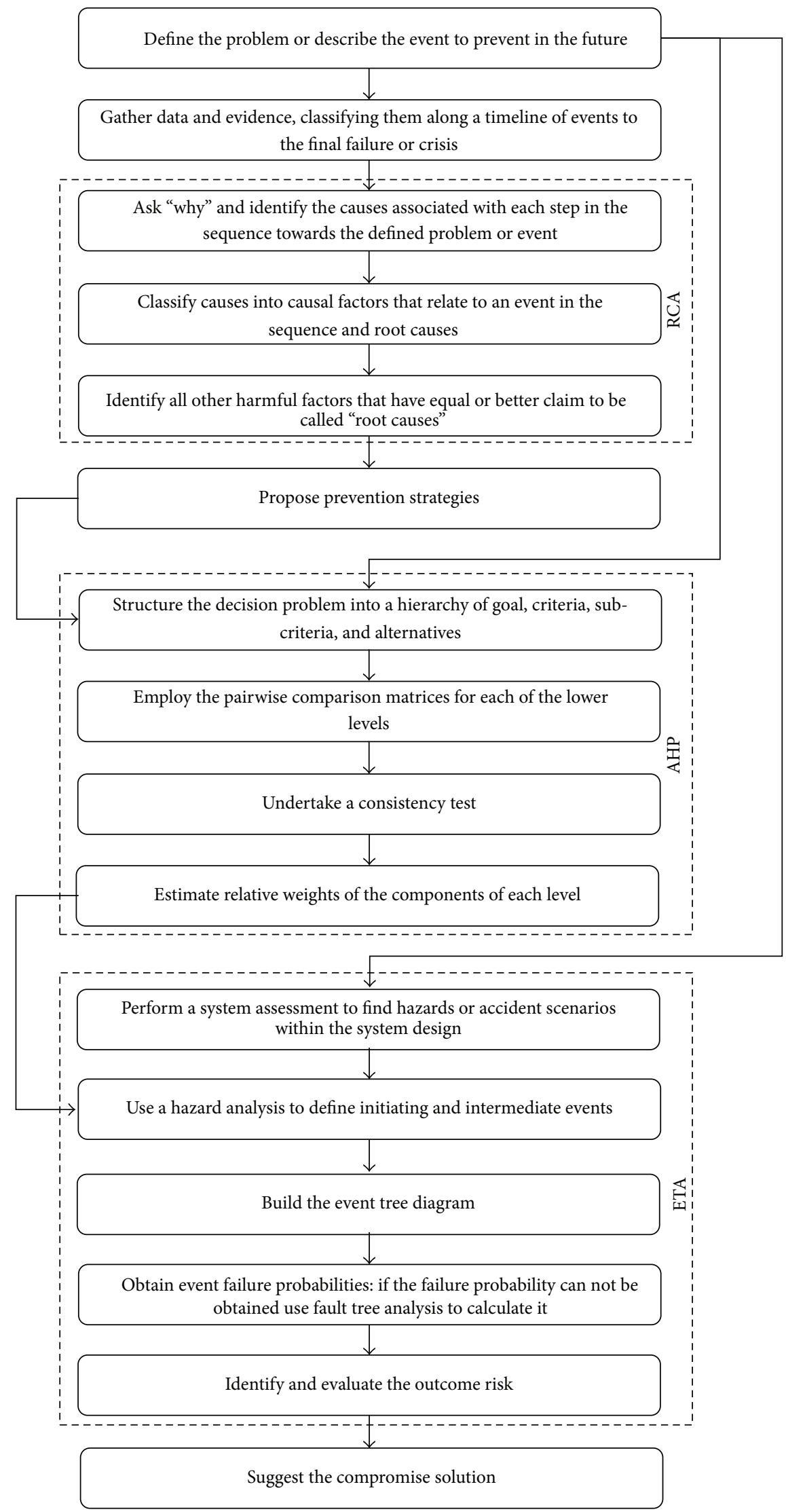

FIGURE 1: Methodology for laboratory fire safety strategies reducing the risk of fire accidents. 
TABLE 1: Fundamental scale of the AHP [8].

\begin{tabular}{|c|c|c|}
\hline $\begin{array}{l}\text { Intensity of } \\
\text { importance }\end{array}$ & Definition & Explanation \\
\hline 1 & Equal importance & Two activities contribute equally to the objective \\
\hline 2 & Weak & - \\
\hline 3 & Moderate importance & $\begin{array}{l}\text { Experience and judgment slightly favor one activity } \\
\text { over another }\end{array}$ \\
\hline 4 & Moderate plus & - \\
\hline 5 & Strong importance & $\begin{array}{l}\text { Experience and judgment strongly favor one activity } \\
\text { over another }\end{array}$ \\
\hline 6 & Strong plus & - \\
\hline 7 & Very strong or demonstrated importance & $\begin{array}{l}\text { An activity is favored very strongly over another; its } \\
\text { dominance is demonstrated in practice }\end{array}$ \\
\hline 8 & Very, very strong & - \\
\hline 9 & Extreme importance & $\begin{array}{l}\text { The evidence favoring one activity over another is of the } \\
\text { highest possible order of affirmation }\end{array}$ \\
\hline Reciprocals of above & $\begin{array}{l}\text { If activity } i \text { has one of the above nonzero numbers } \\
\text { assigned to it when compared with activity } j \text {, then } j \text { has } \\
\text { the reciprocal value when compared with } i\end{array}$ & A reasonable assumption \\
\hline Rationales & Ratios arising from the scale & $\begin{array}{l}\text { If consistency were to be forced by obtaining numerical } \\
\text { values to span the matrix }\end{array}$ \\
\hline
\end{tabular}

of the criteria and subcriteria was rated using the nine-point scale proposed by Saaty [8], as shown in Table 1, which shows the relative importance ranging from equal, moderate, strong, and very strong to extreme by $1,3,5,7$, and 9 , respectively. The intermediate values between two adjacent levels are represented by $2,4,6$, and 8 .

2.3. Event Tree Analysis. Event tree analysis (ETA) is an inductive technique intended to examine a sequence of events and their probability of occurrence. In this work, an event tree starts with an initiating event, such as a component failure, and then the consequences of the event are followed through a series of possible paths. Each path is assigned a probability of occurrence, and the probabilities of the various outcomes are calculated.

\section{Results and Discussion}

3.1. Root Cause Analysis. The task performance team reviewed one hundred and thirty-nine (139) lab fire accidents from the literature and their root causes were collated involving fire origins, causes, and prevention strategies demonstrated in Tables 2-3 and Figures 2-7.

Table 2 shows the number of fire accidents and their origins; fire accidents occurred most frequently in chemistry laboratories, at a rate of about $68.3 \%$, or 95 cases, much more than in physical (24 cases, $17.3 \%$ ) and biological (20 cases, $14.4 \%$ ) laboratories. Among the 95 cases, 23 (24.2\%) were caused by electrical devices, and 44 (46.3\%) were at the locations of the desk, hood, and storage places, due to inflammable materials used. Chemistry laboratories, by their nature, are of primary concern with regard to fire accidents; they may be highly destructive as leading to explosion and serious threat to human life, when they occurred. The causes
TABLE 2: Number of fire accidents by fire origin.

\begin{tabular}{lccc}
\hline Location & Chemical & $\begin{array}{c}\text { Lab type } \\
\text { Biological }\end{array}$ & Physical \\
\hline Desk & 16 & 1 & 1 \\
Hood & 13 & 1 & 0 \\
Biosafety hood & 0 & 5 & 0 \\
Storage place & 15 & 0 & 2 \\
Electrical device & 23 & 6 & 14 \\
Equipment & 12 & 1 & 1 \\
Water tank & 2 & 0 & 0 \\
Exhaust duct & 0 & 0 & 1 \\
Trash can & 1 & 1 & 0 \\
Floor & 6 & 0 & 2 \\
Others & 7 & 5 & 3 \\
\hline Total & 95 & 20 & 24 \\
\hline
\end{tabular}

of lab fire accidents can be classified into five categories, that is, chemical reaction fires, static electricity fires, equipment failure fires, fire due to operational errors (man-made fire), and fires caused by nature disaster. Chemical reaction fires are the most frequent type of fire, with 64 cases, and static electricity fires are the second, with 27 cases, as shown in Table 3. Chemical reaction and static electricity fires together account for $66 \%$ of the total cases, much more than those due to operational error (24 cases, $17 \%$ ) and equipment failure (10 cases, 7\%). Only one fire was caused by natural disaster the massive 921 earthquake which happened in Taiwan on September 21, 1999, with a magnitude of 7.6 on the Richter scale. Figure 2 shows details of the ignition factors causing chemical reaction fires, where runaway chemical reaction (29\%) and the release of flammable materials (21\%) are 
TABLE 3: Cause of fire accidents in laboratory.

\begin{tabular}{|c|c|c|c|c|c|c|c|}
\hline \multirow{2}{*}{ Laboratory } & \multicolumn{7}{|c|}{ Cause } \\
\hline & Chemical reaction & Static electricity & Equipment failure & Operational error & Nature disaster & Others & Total \\
\hline Chemical & 54 & 13 & 6 & 14 & 1 & 7 & 95 \\
\hline Physical & 3 & 10 & 2 & 5 & 0 & 4 & 24 \\
\hline Biological & 7 & 4 & 2 & 5 & 0 & 2 & 20 \\
\hline
\end{tabular}

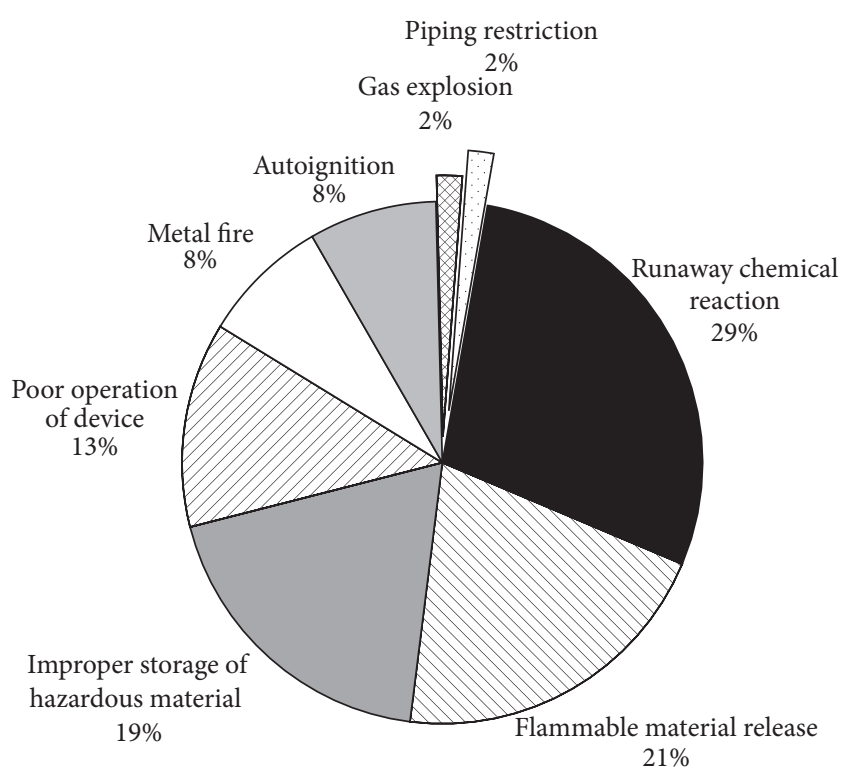

FIgURE 2: Percentage breakdown of root causes in chemical reaction fire casualties.

the most. The causes of static electricity fires, as shown in Figure 3, are mainly from short circuits (21 instances, $78 \%$ ), electric wire overloading (three instances, $11 \%$ ), and electrical failure (excluding short circuits and ground faults). Figure 4 indicates that the major causes of equipment failure fires were malfunctions (four instances) and overheating due to heater failure (three instances). The analysis of the 24 man-made fires shows that these accidents mainly resulted from human error rather than conscious risk taking; the main factors were negligence (14 instances), experimental mistakes, or misunderstanding the SOP (seven instances) and disobeying the safety rules. A fishbone diagram is thus developed, shown in Figure 5, to more clearly illustrate the relationship between an "effect" and all the possible "causes." And accordingly, the accident prevention strategies, in Figure 6, are also proposed. From above, it is clear that fire accidents have some form of human error involved, whether they are chemical experiment or electric fires. It is recommended that lab safety implementation plans must take human fallibility into consideration, including being overly optimistic about our ability to control our environments.

3.2. AHP Analysis. AHP can model a complex problem in a simple hierarchy form for decision making. Our goal is shown at the top of Figure 9. When we consider the factors affecting fire prevention ability, five main criteria are found at

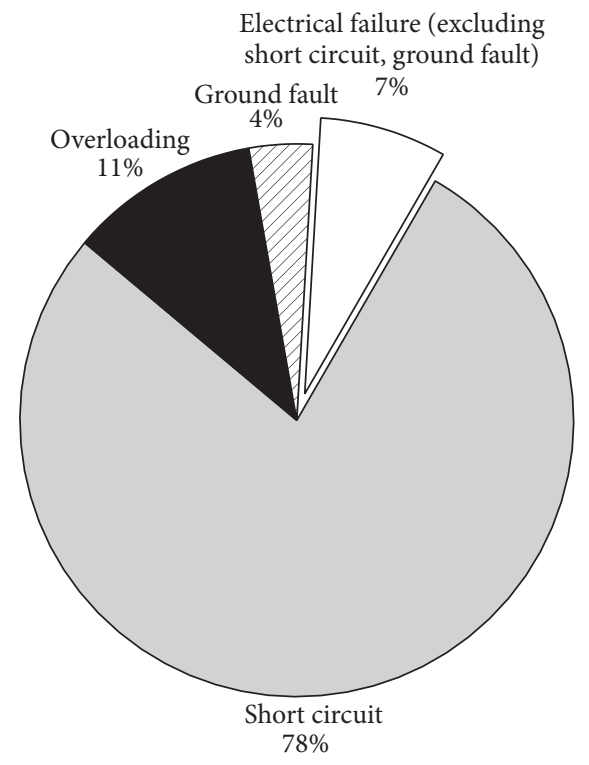

FIGURE 3: Percentage breakdown of root causes in static electricity fire casualties.

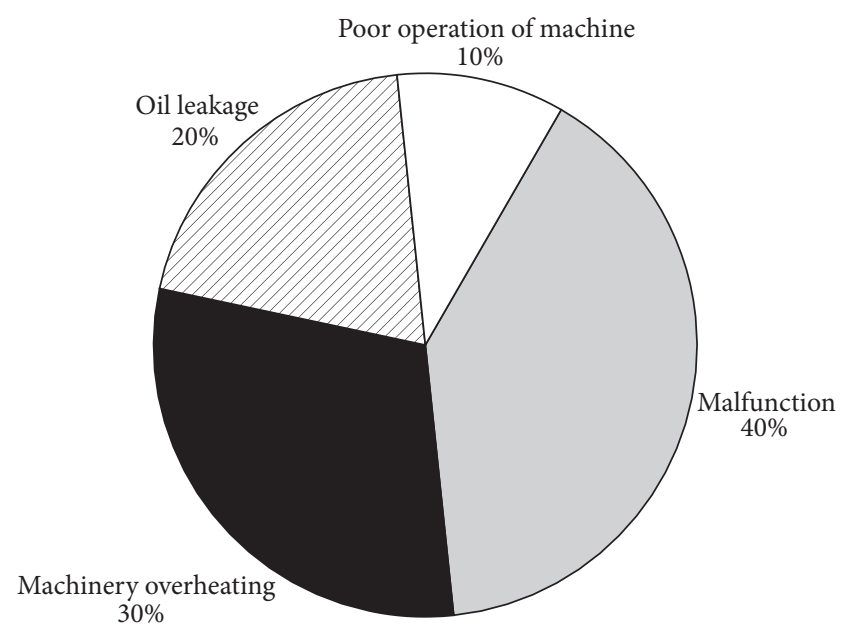

FIgURE 4: Percentage breakdown of root causes in equipment failure fire casualties.

level 1: man-made fire prevention (MMFP), mechanical and electrical fire prevention (MEFP), chemical fire prevention (CFP), personal protective equipment (PPE), and disaster experience learning (DEL). Each criterion is further divided into a number of subcriteria at level 2. The consistent data from 15 respondents are used to make pairwise comparisons between decision alternatives and criteria using a scaling ratio 


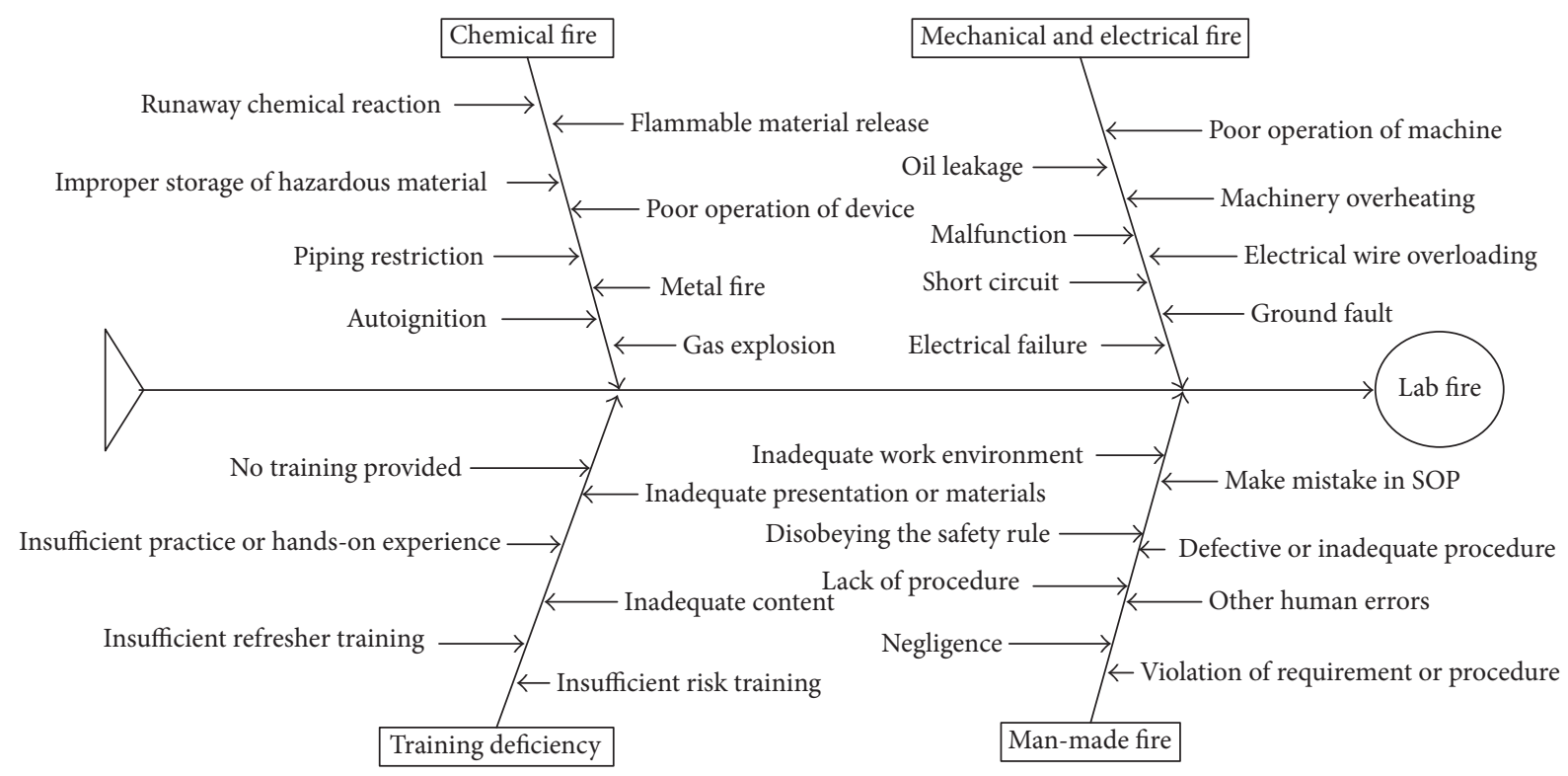

Figure 5: Lab fire cause and effect fishbone diagram.

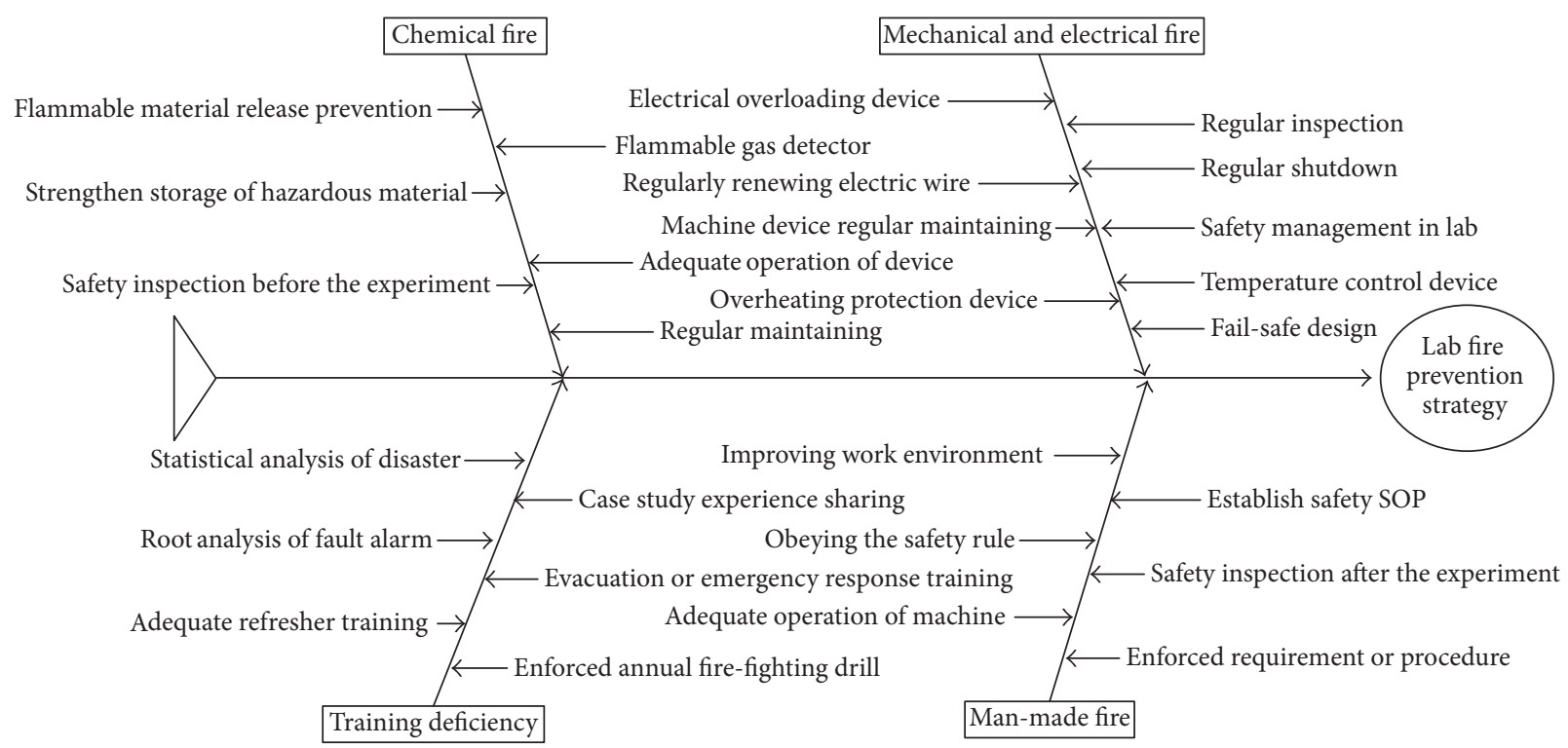

FIGURE 6: Lab fire prevention strategy fishbone diagram.

for the weighting of attributes. As discussed previously, we construct pairwise comparison matrices (main criteria and subcriteria) for each response. The judgment matrices are computed by using a commercial software package, Power Choice, to prioritize the criteria and alternatives. The local priority weights of all the main criteria and subcriteria are first calculated and then combined with all successive hierarchical levels in each matrix to obtain a global priority vector. The higher the mean weight of the global priority vector, the greater the relative importance. This will help lab safety decision makers find the most important control elements in their decision-making process. As shown in Table 6, the local priority of the main criteria weights from the lowest of 0.132 to the highest of 0.263 , and the global priority weights from the lowest of 0.012 to the highest of 0.064. Chemical fire prevention (CFP) with local priority of 0.263 is evaluated as the main factor for respondents when selecting their fire prevention strategy, followed by MEFP (0.261) and PPE (0.202), and DEL (0.132); identifying risks in the working environment $(0.062)$ is seen as the most effective way of the subcriteria items in CFP category, carrying out safety inspections after experiments (0.058) in MMFP category, strengthening maintenance and safety inspection intensity for electrical equipment (0.064) in MEFP category, developing a standard operating procedure for laboratory facilities (0.048) in PPE category, and evacuation 


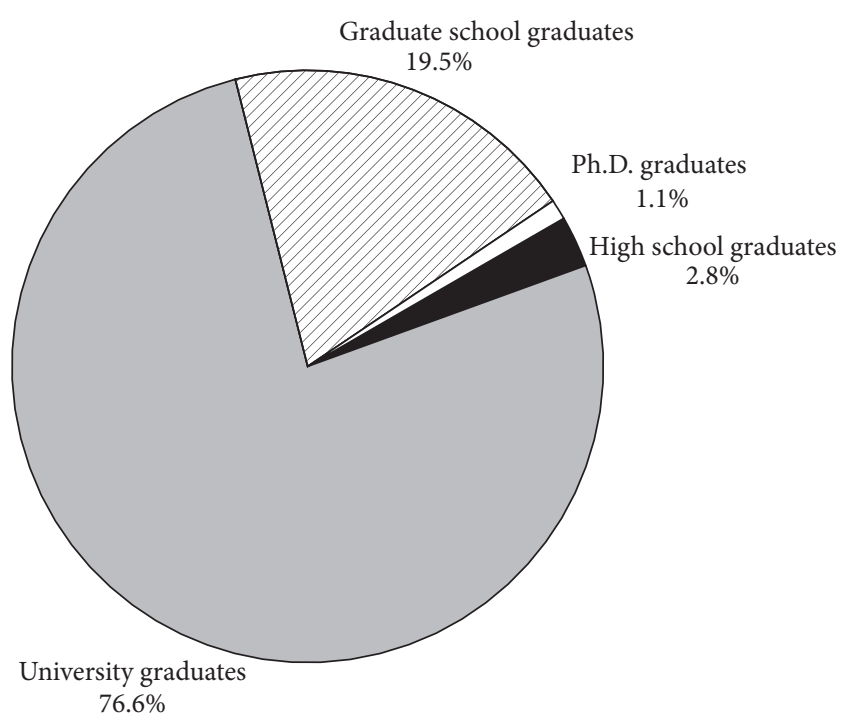

FIgURE 7: Percentage breakdown of respondents' education background.

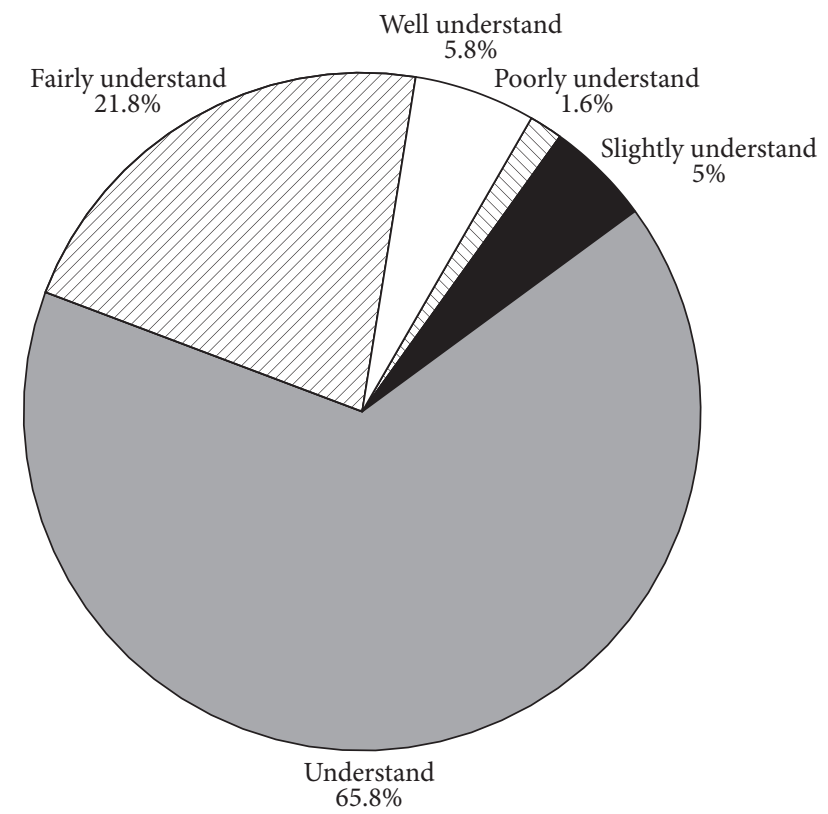

FIGURE 8: Percentage breakdown of the views of respondents on their understanding of risks.

and emergency response training (0.034) in DEL category. The weights of top 10 subcriteria are presented in Table 7 in descending order. The proposed priorities of these prevention strategies could assist EH\&S officers and lab employees in selecting appropriate strategies for enhancing fire safety in laboratories. However, it is worth noting that eight of the top 10 subcriteria are either management or staff-education strategies, and only two are technology related.

A general questionnaire survey of 641 respondents (all with lab operating experience) about safety knowledge and training was conducted and 573 valid samples were collected. The results are shown in Figures 7 and 8 and Tables 4 and 5.
Figure 7 presents that $76.6 \%$ of the respondents were university students, $19.5 \%$ graduate school students, $2.8 \%$ senior high school students, and 1\% Ph.D. students. Table 4 indicates that $66.7 \%$ of the respondents received laboratory safety training, and more than $57.6 \%$ of them felt that it was important, although $6.8 \%$ said that they felt they did not benefit from it; research showed that, even under optimal training circumstances, individual differences related to a person's intention to learn play an important role in training effectiveness. On the other hand, nearly $33.3 \%$ of the respondents did not receive the laboratory safety training, but $60 \%$ of them agreed that it was important for improving laboratory safety. The Mann-Whitney $U$ test for both types of respondents was conducted to quantify, subjectively and objectively, the effects of laboratory safety training. It revealed no significant differences $(p>0.05)$ in the satisfaction with the effect of safety education and perception of their safety behaviors. In terms of whether the respondents fully understood the fire dangers prevention and protection, before doing experiments, Figure 8 indicates that $27.6 \%$ of respondents thought so; most of laboratory staff replied that they realized the importance of accident prevention, but the results implied that $72.4 \%$ of the staff still perceive risks in the laboratory operations; Table 5 presents that most respondents $(81.7 \%)$ knew the location of the safety protective equipment, and approximately $88.7 \%$ understood their standard operating procedures (SOPs), but only $42.2 \%$ had the experience of using the safety protective equipment. These results indicate that most training programs need improvement, especially for safety skills training curricula. Nearly $57.8 \%$ of respondents felt that there is room for improvement of their current lab safety training programs.

3.3. Event Tree Analysis. It is well known that hood is a critical part when conducting chemical experiments. Unfortunately, there is usually no fire protection within it. Previously we have found that fire accidents occurred frequently in chemistry laboratories. Therefore, we proposed hood safety improvement as a compensation for the insufficiency of management system to improve the fire safety level, namely, installing fire prevention equipment in the hood as proactive preventions from fire accidents: fire detector, automatic sprinkler, and manual extinguisher. ETA was used to explore the feasibility of reducing the risk of fire. The probability of extinguishing a fire due to fire detectors [27], automatic sprinklers [28], laboratory personnel, and fire brigades [29] was set as 0.94, $0.81,0.51$, and 0.97 , respectively. The damage is divided into two in this work: research data loss and equipment property damage, with range from 1 to 5 being used for the degree damage, in order to quantitatively assess the consequences of a fire. Damage to research data is considered to be the most important event, since research data from years of work is difficult to recover if it is lost, while laboratory equipment is easier to replace. Degree of damage caused by fire in a laboratory is presented in Table 8 .

Figure 10 shows the event tree analysis for a fire occurring in a hood without a fire system. The ETA results indicate that when there is no fire extinguisher system in the hood, 


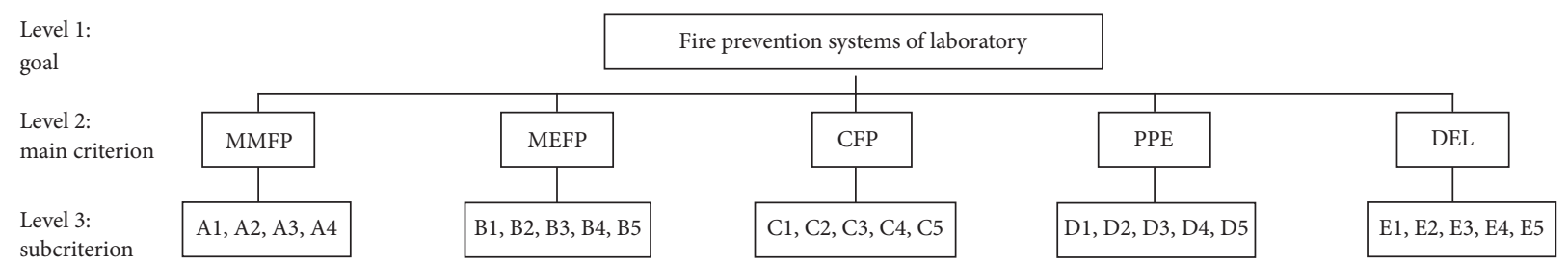

Legend for level 2, 3 attributes:

MMFP: man-made fire prevention

MEFP: mechanical and electrical fire prevention

CFP: chemical fire prevention

PPE: personal protective equipment

DEL: disaster experience learning

A1: practice safety inspections after experiments

A2: establish complete safety guide

A3: establish complete emergency response plan for disasters

A4: set up the disaster announcement procedures and emergency telephone number labels
B1: reinforce the protective devices for mechanical equipment

B2: strengthen maintenance and safety inspection intensity for electrical equipment

B3: fail-safe design

B4: strengthen the safety management of the laboratory

B5: increase the number of the fire detectors and fire extinguishers

$\mathrm{C} 1$ : identify the risks in the working environment

$\mathrm{C} 2$ : enhance the safety design of storage devices

C3: carry out safety inspections and labeling of storage devices

C4: strengthen the identification of hazard materials information using the Material Safety Data Sheets (MSDS) for chemicals

C5: enhance the detection technology in the working environment
D1: the personnel protective equipment regular maintenance

D2: develop the standard operation procedures for laboratory facilities

D3: strengthen the instrument operating education and

training

D4: strengthen the health and safety education and training

D5: give safety lectures to new employees

E1: cause analysis of false alarm

E2: develop the accident investigation mechanism and database

E3: experience sharing

E4: evacuation and emergency response training

E5: carry out annual fire-fighting drill and check system

FIGURE 9: AHP model for the prioritization of the fire accident prevention strategies in lab.

\begin{tabular}{|c|c|c|c|c|c|c|c|c|c|}
\hline $\begin{array}{c}\text { Initiating } \\
\text { event }\end{array}$ & \multicolumn{4}{|c|}{ Pivotal events } & \multicolumn{2}{|c|}{ Probability } & \multicolumn{2}{|c|}{ Consequence } & \multirow{2}{*}{ Risk } \\
\hline & 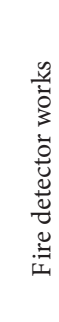 & 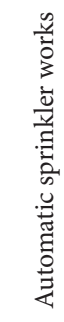 & 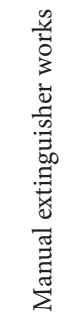 & 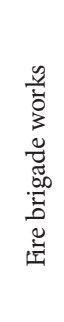 & 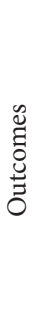 & 正 & 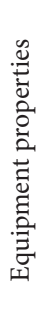 & 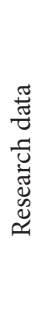 & \\
\hline & & \multirow{2}{*}{0.81} & & & 1 & 0.7614 & 3 & 2 & 3.8070 \\
\hline & \multirow[t]{4}{*}{0.94} & & \multirow{2}{*}{0.51} & & 2 & 0.0911 & 3 & 3 & 0.5465 \\
\hline & & \multirow[t]{3}{*}{0.19} & & \multirow{2}{*}{0.97} & 3 & 0.0849 & 4 & 4 & 0.6791 \\
\hline & & & 0.49 & & 4 & 0.0026 & 5 & 5 & 0.0263 \\
\hline & & & \multirow[t]{2}{*}{0.51} & & 5 & 0.0306 & 3 & 3 & 0.1836 \\
\hline & \multirow[t]{2}{*}{0.06} & & & \multirow{2}{*}{0.97} & 6 & 0.0285 & 4 & 4 & 0.2281 \\
\hline & & & 0.49 & & 7 & 0.0009 & 5 & 5 & 0.0088 \\
\hline
\end{tabular}

FIGURE 10: Results of the ETA (for the hood without a fire system). 


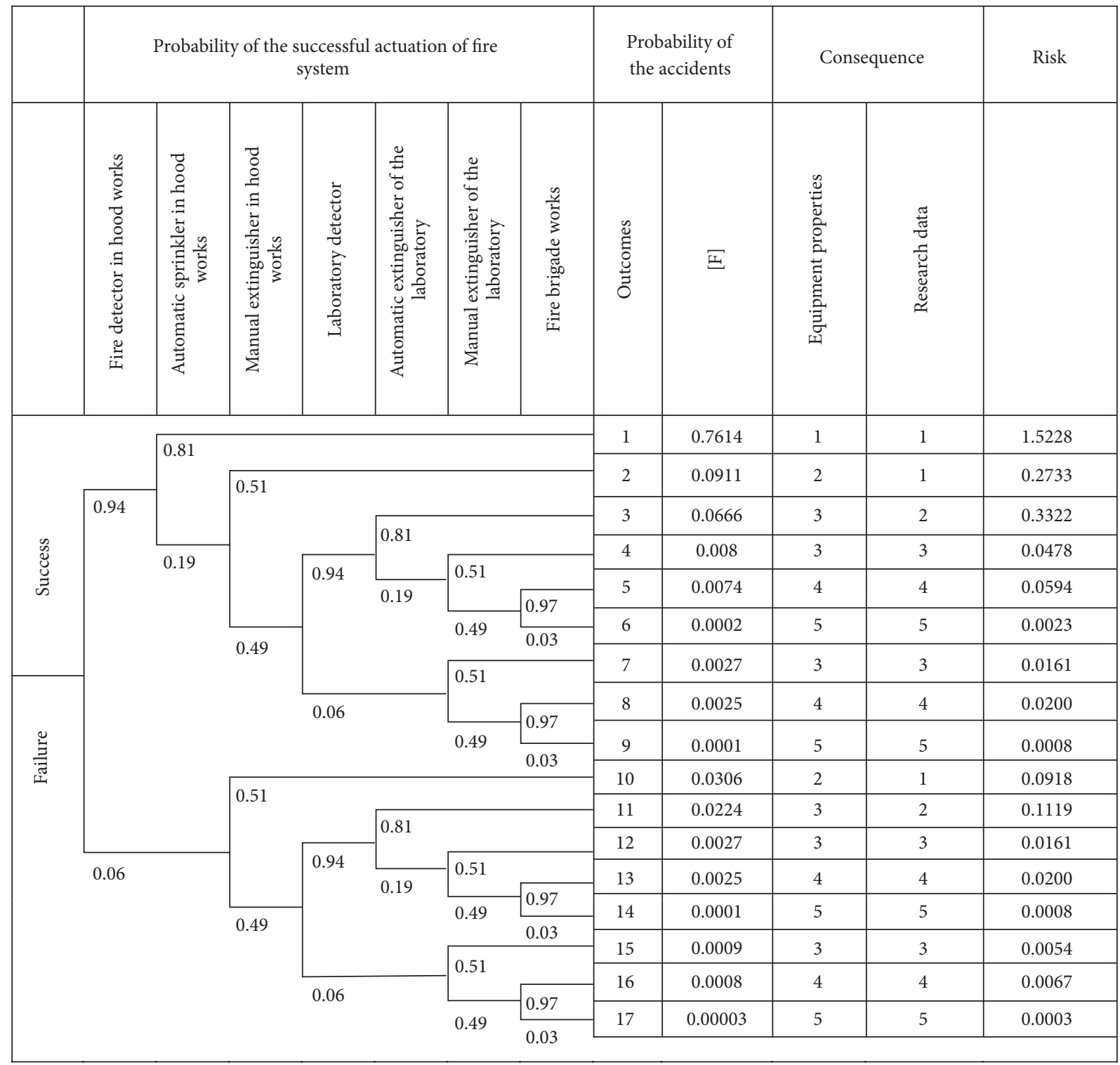

Figure 11: Results of the ETA (for the hood with a fire system).

TABLE 4: The effect of laboratory safety training.

Do you benefit from laboratory safety training course?

\begin{tabular}{|c|c|c|c|c|c|c|}
\hline Received the training course & & Strongly disagree & Disagree & Neither agree nor disagree & Agree & Strongly agree \\
\hline Yes & Number (\%) & $5(1.3 \%)$ & $21(5.5 \%)$ & $136(35.6 \%)$ & $164(42.9 \%)$ & $56(14.7 \%)$ \\
\hline No & Number (\%) & $7(3.7 \%)$ & $4(2.1 \%)$ & $66(34.6 \%)$ & $72(37.7 \%)$ & $42(22.0 \%)$ \\
\hline
\end{tabular}

TABLE 5: Survey on knowledge of the safety facility system.

\begin{tabular}{|c|c|c|}
\hline Question & Yes & No \\
\hline $\begin{array}{l}\text { Do you know the location of the safety facility system (fire extinguisher, fire alarm button, emergency } \\
\text { safety shower, personnel protective equipment, etc.)? }\end{array}$ & $468(81.7 \%)$ & $105(18.3 \%)$ \\
\hline Do you understand the standard operating procedure (SOP) of the safety facility system? & $508(88.7 \%)$ & $65(11.3 \%)$ \\
\hline Do you have experience with the safety facility system? & $242(42.2 \%)$ & $331(57.8 \%)$ \\
\hline
\end{tabular}




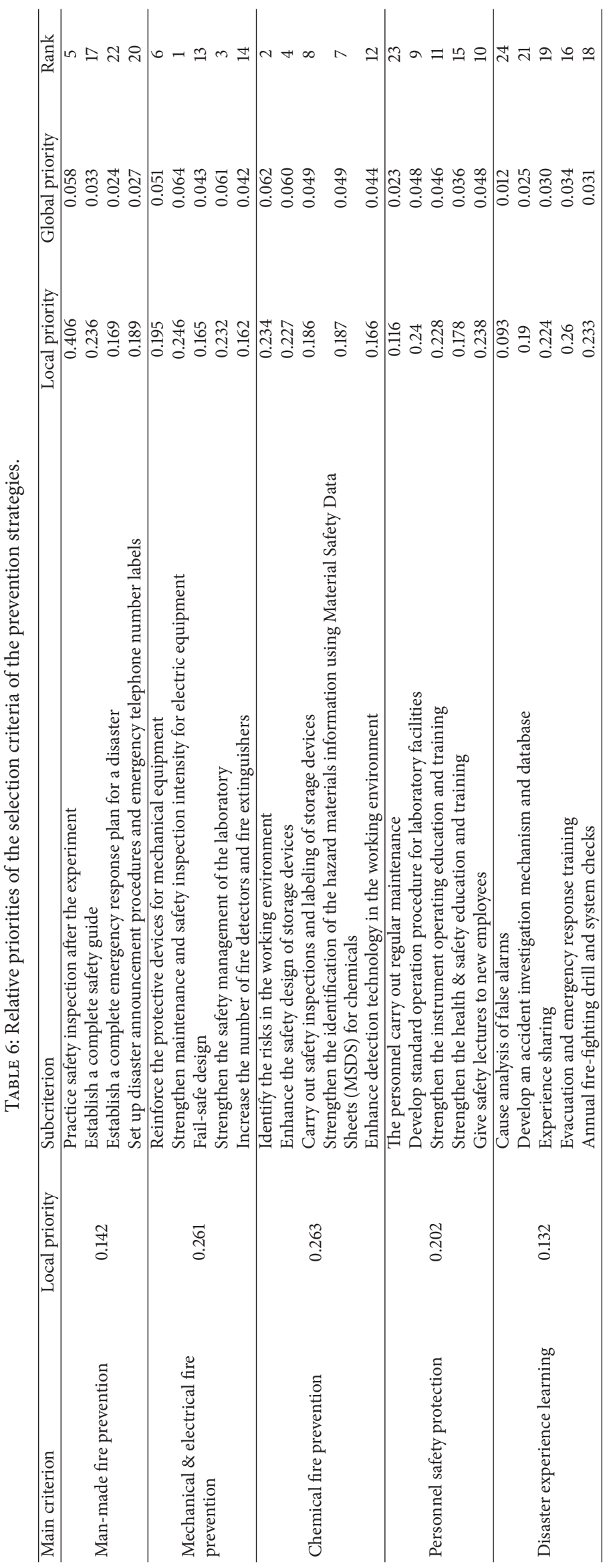


TABLE 7: Global percentage weights of the subcriteria of the hierarchy tree in descending order.

\begin{tabular}{llc}
\hline Rank & Subcriteria & Global percentage weight \\
\hline 1 & Strengthen maintenance and safety inspection intensity for electrical equipment & $6.4 \%$ \\
2 & Identify the risks in the working environment & $6.2 \%$ \\
3 & Strengthen the safety management of the laboratory & $6.1 \%$ \\
4 & Enhance the safety design of storage devices & $6.0 \%$ \\
5 & Practice safety inspections after experiments & $5.8 \%$ \\
6 & Reinforce the protective devices for mechanical equipment & $4.3 \%$ \\
7 & Strengthen identification of the hazard materials information using the Material & $4.9 \%$ \\
8 & Safety Data Sheets (MSDS) for chemicals & $4.9 \%$ \\
9 & Carry out safety inspections and labeling of storage devices & $4.8 \%$ \\
10 & Develop standard operation procedures for laboratory facilities & $4.8 \%$ \\
\hline
\end{tabular}

TABLE 8: Degree of damage caused by fire in a laboratory.

\begin{tabular}{lcl}
\hline $\begin{array}{l}\text { Damage } \\
\text { category }\end{array}$ & $\begin{array}{c}\text { Degree of } \\
\text { damage }\end{array}$ & Description of damage \\
\hline \multirow{2}{*}{ Property } & 1 & Less than 1,000 USD: nondamaged \\
& 2 & $1,000 \sim 5,000$ USD: slightly damaged \\
& 3 & $5,000 \sim 50,000$ USD: moderately damaged \\
& 5 & Mo,000 100,000 USD: heavily damaged \\
& 1 & $100 \%$ restorable \\
Research & 2 & $80 \%$ restorable \\
data & 3 & $50 \%$ restorable \\
& 4 & $20 \%$ restorable \\
& 5 & $0 \%$ restorable
\end{tabular}

and when the fire extinguisher system in laboratory fails, then outcomes 4 and 7 arise, and the total risk associated with a failed fire extinguisher system is $0.026+0.009=$ 0.035 . But when fire detectors and a fire extinguisher system are installed, three additional pivotal events are identified; namely, the fire detector works in the hood, the automatic sprinkler works, and the manual extinguisher works. The ETA for this case indicates that when the fire extinguisher system failure happens, as shown in Figure 11, the possible outcomes are 6, 9, 14, and 17. The total risk for the fire extinguisher failure is 0.0042 . The results indicate that the total risk of a fire occurring in hood decreases from 0.0350 to 0.0042 when actions to improve hood safety are taken. According to these results, ETA, incorporated into the proposed management model, is very useful to evaluate the probability of whether safety strategies can successfully control the fire accidents or additional design is needed.

\section{Conclusions}

A system-based management model for lab fire prevention was investigated which combines RCA, AHP, and ETA with the information of questionnaire surveys in a loop. First, the information of 139 lab fire accidents was reviewed; a fishbone diagram was used to analyze the causes leading to accidents and prevention strategies were also developed; AHP with various levels of criteria was used to evaluate the priority of these strategies. We also found that, no matter what reasons, human error could be inevitable and it has to be considered seriously. Additional fire prevention equipment was thus proposed to be installed in the lab hood. ETA, an inductive management technique, was applied, to explore how effective these installations can achieve. The risks drop tremendously from 0.035 to 0.0042 . Fire risks could largely be avoided if good engineering design is also involved in the safety management program. Combining root cause analysis (RCA), analytic hierarchy process (AHP), and event tree analysis (ETA) in a loop is able to develop and prioritize prevention strategies and more specifically evaluate whether these strategies can successfully control fire accidents or specific installation is needed.

\section{Competing Interests}

The authors declare that there is no conflict of interests regarding the publication of this paper.

\section{Acknowledgments}

This study was supported by the Ministry of Science and Technology of Taiwan under Projects MOST 103-2221-E-327004 and MOST 104-3113-E-006-019-CC2.

\section{References}

[1] A. Keith Furr, CRC Handbook of Laboratory Safety, CRC Press, 5 th edition, 2000.

[2] R. J. Alaimo, Handbook of Chemical Health and Safety, Oxford University Press, Oxford, UK, 2001.

[3] Environment, Health, and Safety Committee, Fire Safety in Chemical Laboratories, Royal Society of Chemistry, London, UK, 2007.

[4] Y. C. Chien, C. P. Chang, Y. C. Lin, H. S. Liu, and K. C. Lee, “The characteristics and potential causes of laboratory incident and injury in Taiwan," in Proceedings of the the Occupational Safety \& Hygiene International Symposium, 2002. 
[5] C. Shih, Y. C. Chien, T. P. Chia, and C. P. Chang, "Initial review of emergency response procedure for laboratories on campus," in Proceedings of the Occupational Safety \& Hygiene International Symposium, 2002.

[6] S. Y. Lin, Fire risk assessment of fume hood in laboratories [M.S. thesis], National Kaohsiung First University of Science and Technology, 2008.

[7] J. I. Chang and C.-C. Lin, "A study of storage tank accidents," Journal of Loss Prevention in the Process Industries, vol. 19, no. 1, pp. 51-59, 2006.

[8] T. L. Saaty, The Analytic Hierarchy Process: Planning, Priority Setting, Resource Allocation, McGraw-Hill, 1980.

[9] T. J. Crowe, J. S. Noble, and J. S. Machimada, "Multi-attribute analysis of ISO 9000 registration using AHP," International Journal of Quality and Reliability Management, vol. 15, no. 2, pp. 205-222, 1998.

[10] S.-O. Cheung, T.-I. Lam, M.-Y. Leung, and Y.-W. Wan, "An analytical hierarchy process based procurement selection method," Construction Management and Economics, vol. 19, no. 4, pp. 427-437, 2001.

[11] M. Hastak, "Advanced automation or conventional construction process?" Automation in Construction, vol. 7, no. 4, pp. 299314, 1998.

[12] E. W. L. Cheng and H. Li, "Construction partnering process and associated critical success factors: quantitative investigation," Journal of Management in Engineering, vol. 18, no. 4, pp. 194202, 2002.

[13] S. K. Lee, Y. J. Yoon, and J. W. Kim, "A study on making a longterm improvement in the national energy efficiency and GHG control plans by the AHP approach," Energy Policy, vol. 35, no. 5, pp. 2862-2868, 2007.

[14] J. K. W. Wong and H. Li, "Application of the analytic hierarchy process (AHP) in multi-criteria analysis of the selection of intelligent building systems," Building and Environment, vol. 43, no. 1, pp. 108-125, 2008.

[15] C.-M. Chiang and C.-M. Lai, "A study on the comprehensive indicator of indoor environment assessment for occupants' health in Taiwan," Building and Environment, vol. 37, no. 4, pp. 387-392, 2002.

[16] K.-F. Chang, C.-M. Chiang, and P.-C. Chou, "Adapting aspects of GBTool 2005-searching for suitability in Taiwan," Building and Environment, vol. 42, no. 1, pp. 310-316, 2007.

[17] R. M. Tavares, J. M. L. Tavares, and S. L. Parry-Jones, "The use of a mathematical multicriteria decision-making model for selecting the fire origin room," Building and Environment, vol. 43, no. 12, pp. 2090-2100, 2008.

[18] N. S. Arunraj and J. Maiti, "Risk-based maintenance policy selection using AHP and goal programming," Safety Science, vol. 48, no. 2, pp. 238-247, 2010.

[19] S. D. Novack, N. O. Siu, and S. G. Hill, "The use of event trees in oil spill prevention applications," International Oil Spill Conference Proceedings, vol. 1997, no. 1, pp. 527-534, 1997.

[20] M. Abdelgawad and A. R. Fayek, "Comprehensive hybrid framework for risk analysis in the construction industry using combined failure mode and effect analysis, fault trees, event trees, and fuzzy logic," Journal of Construction Engineering and Management, vol. 138, no. 5, pp. 642-651, 2012.

[21] C. Maio, M. C. Liu, and Y. C. Peng, "The practice on laboratory risk assessment," Chemical Engineering, vol. 49, no. 5, pp. 62-73, 2002.
[22] AS/NZS 4360: 2004 Risk Management, 2004: Standards Australia and Standards New Zealand.

[23] C. W. Lin, Y. C. Kuo, S. H. Kuo, and H. C. Wu, "Investigation on fires and explosions at university laboratories related to chemicals," in Proceedings of the Annual Conference of the Chemical Engineering Safety, 2003.

[24] J. Y. Peng and R. S. Sheu, "A study of risk management on the university campus safety," in Proceedings of the International Seminar on Fundamental University Education, 2006.

[25] J. Zakzeski, "Improving engineering research laboratory safety by addressing the human aspects of research management," Journal of Chemical Health and Safety, vol. 16, no. 3, pp. 5-20, 2009.

[26] T.-C. Wu, C.-W. Liu, and M.-C. Lu, "Safety climate in university and college laboratories: impact of organizational and individual factors," Journal of Safety Research, vol. 38, no. 1, pp. 91-102, 2007.

[27] R. W. Bukowski, E. K. Budnick, and C. F. Schemel, "Estimates of operation reliability of fire protection systems," in Proceedings of the International Conference on Fire Research and Engineering, 1999.

[28] W. E. Koffel, "Reliability of automatic sprinkler system," in Proceedings of 2006 Fire Supersession and Detection Research Application Symposium, 2006.

[29] Y. Yoshida, "Analysis of simulation evacuation World Trade Center," in Proceedings of the CIB-CTBUH Conference on Tall Buildings: Strategies for Performance in the Aftermath of the World Trade Centre CIB, Kuala Lumpur, Malaysia, October 2003. 


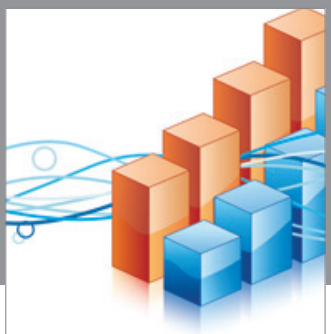

Advances in

Operations Research

vatem alat4

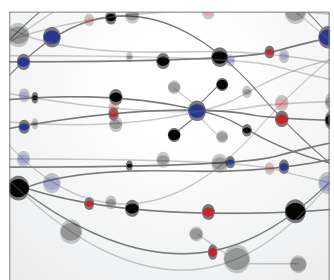

\section{The Scientific} World Journal
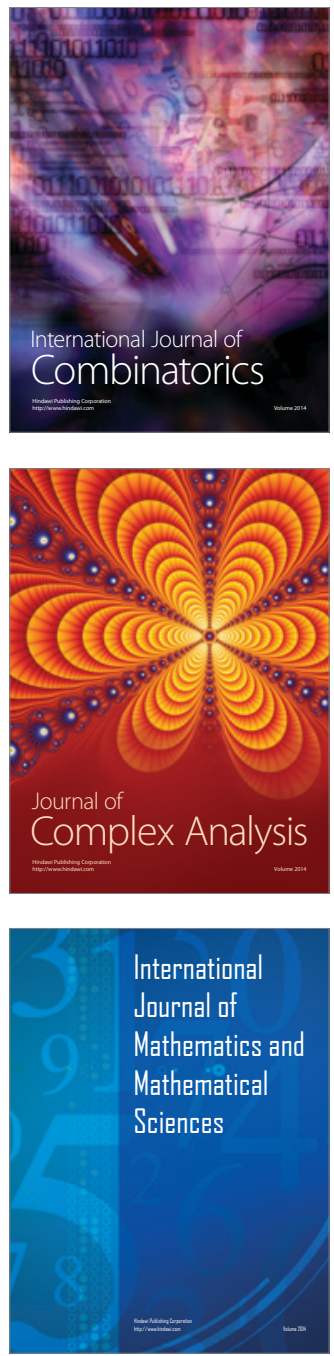
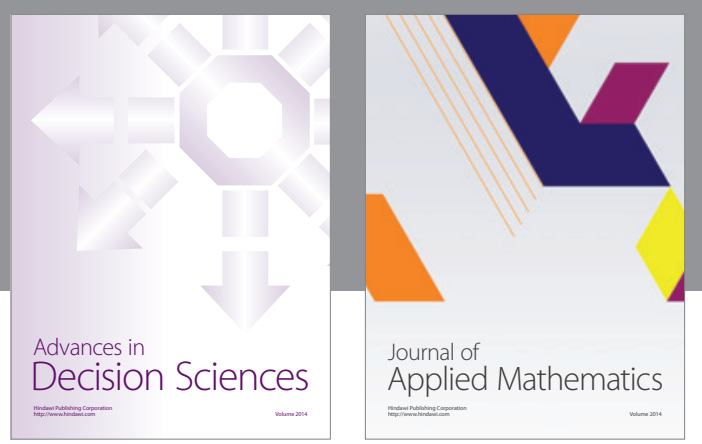

Algebra

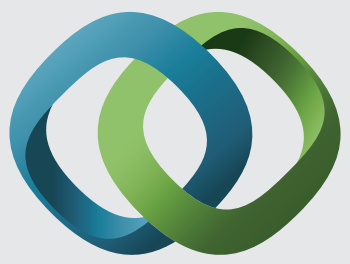

\section{Hindawi}

Submit your manuscripts at

http://www.hindawi.com
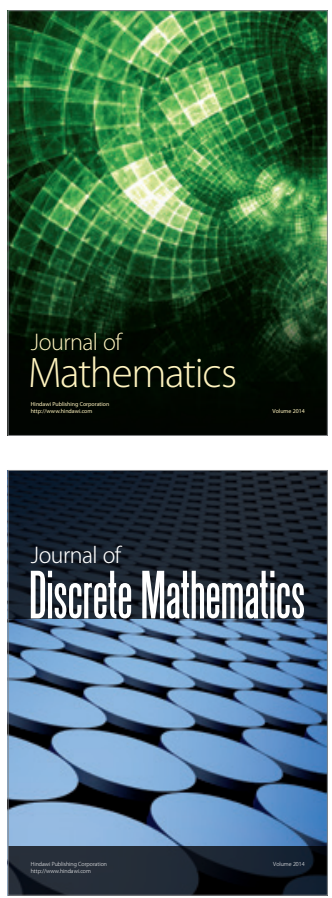

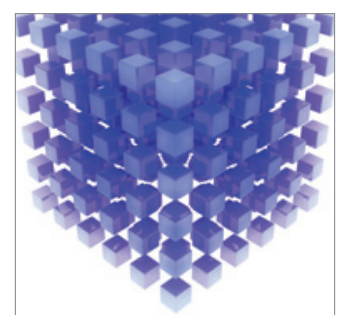

Mathematical Problems in Engineering
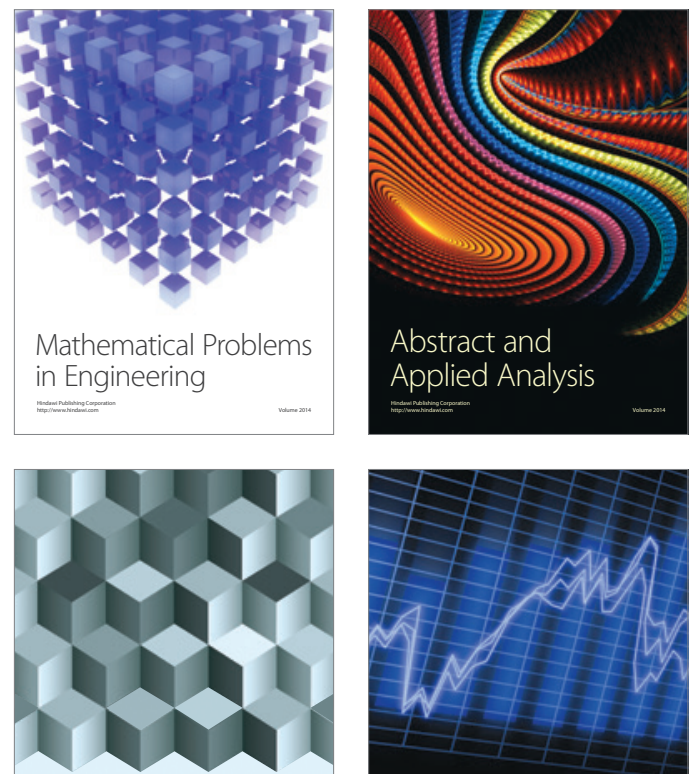

Journal of

Function Spaces

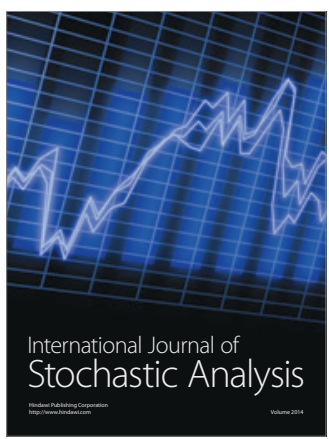

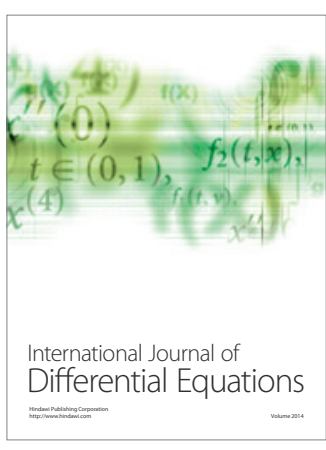
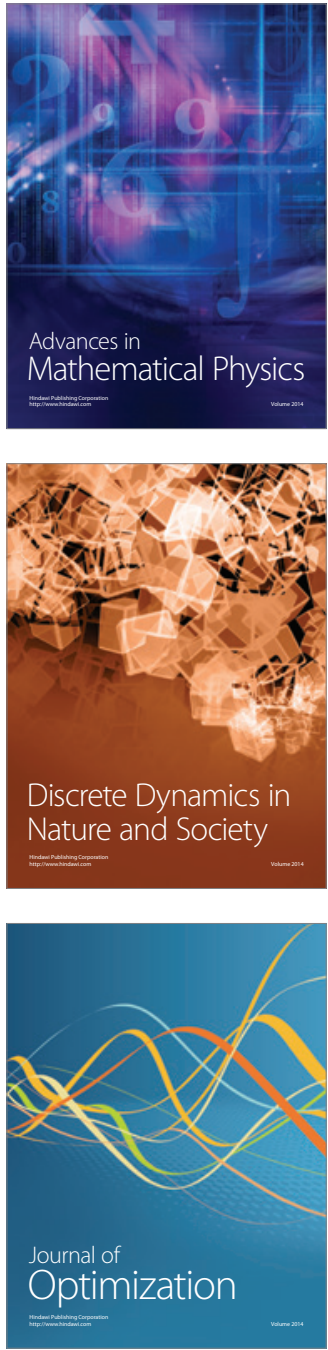